\title{
¿Adenomegalia o adenopatía?
}

\section{Adenomegaly or adenophaty?}

\author{
Alfredo Pinzón-Junca • Bogotá, D.C. (Colombia)
}

DOI: https://doi.org/10.36104/amc.2020.1719

El uso de estos términos puede generar confusión. Conocer su origen y significado puede ayudar a aclararla.

Adenomegalia: (Del latín adeno- 'glándula' + megal 'grande' + iãa; documentado en inglés desde 1957) [inglés: adenomegaly]:

1. s.f. Hipertrofia de una glándula.

2. s.f. Adenopatía.

Adenopatía: (Del latín adeno- 'glándula' + pátheia 'enfermedad'; documentado en francés desde 1855) [inglés: lymphadenopathy, enlarged node]:

1. s.f. Aumento del volumen de un ganglio linfático que puede deberse, entre otras causas, a infecciones, neoplasias del tejido linfático, metástasis tumorales o trastornos inmunitarios.

2. f. Med. Enfermedad de los ganglios, especialmente de los linfáticos.

Sinónimos: adenomegalia, linfadenomegalia, linfadenopatía.

Observación: Desde el punto de vista etimológico, la forma correcta debería ser «linfadenomegalia», pero en la práctica apenas se usa.

Según esto, parece más adecuado utilizar el término adenomegalia para referirse solo al aumento de tamaño del ganglio linfático, y adenopatía para hablar de la enfermedad en dicho órgano. Sin embargo, estas palabras son sinónimos y pueden ser utilizadas indistintamente.

Llama la atención que, como hallazgo aislado e inespecífico, solamente el vocablo adenomegalia aparece en la Clasificación Internacional de Enfermedades (CIE-10: R599). No obstante, este término no se encuentra registrado en el Diccionario de la Real Academia Española de la Lengua (DRAE).

\section{Fuentes}

- Real Academia Nacional de Medicina. Diccionario de Términos Médicos. Editorial Médica Panamericana. 2012

- Diccionario de la Real Academia Española de la Lengua, disponible en: www.rae.es

- McGee S. Evidence-based physical diagnosis. Elsevier Saunders. 2012; p. 215

* Envíe sus inquietudes, sugerencias o comentarios a: contacto@actamedicacolombiana.com - alfpin@hotmail.com Dr. Alfredo Pinzón-Junca: Especialista en Medicina Interna y Psicoanálisis. Hospital Universitario de La Samaritana y Hospital Simón Bolívar. Coordinador del Consejo de Acreditación y Recertificación de la ACMI ${ }^{\circledR}$. Bogotá, D.C. (Colombia).

E-mail: alfpin@hotmail.com

Recibido: 26/II//2020 Aceptado: 4/III/2020 